\title{
Article \\ Determination of Gas Permeation Properties in Polymer Using Capacitive Electrode Sensors
}

\author{
Jaekap Jung ${ }^{1, *}$, Gyunghyun Kim ${ }^{2}$, Gahyoun Gim ${ }^{2} \odot$, Changyoung Park ${ }^{2}$ and Jihun Lee ${ }^{1}$ \\ 1 Hydrogen Energy Materials Research Center, Korea Research Institute of Standards and Science, \\ Daejeon 34113, Korea; ljh93@kriss.re.kr \\ 2 Department of Physics and Research Institute of Natural Science, Gyeongsang National University, \\ Jinju 52828, Korea; 2016010673@gnu.ac.kr (G.K.); cutegosum@gnu.ac.kr (G.G.); parkcy@gnu.ac.kr (C.P.) \\ * Correspondence: jkjung@kriss.re.kr; Tel.: +82-42-868-5759
}

Citation: Jung, J.; Kim, G.; Gim, G.; Park, C.; Lee, J. Determination of Gas Permeation Properties in Polymer Using Capacitive Electrode Sensors. Sensors 2022, 22, 1141. https:// doi.org/10.3390/s22031141

Academic Editor: Jesus Lozano

Received: 6 January 2022

Accepted: 29 January 2022

Published: 2 February 2022

Publisher's Note: MDPI stays neutral with regard to jurisdictional claims in published maps and institutional affiliations.

Copyright: (C) 2022 by the authors. Licensee MDPI, Basel, Switzerland. This article is an open access article distributed under the terms and conditions of the Creative Commons Attribution (CC BY) license (https:// creativecommons.org/licenses/by/ $4.0 /)$.

\begin{abstract}
The objective of this work was to develop an effective technique for characterizing the permeation properties of various gases, including $\mathrm{H}_{2}, \mathrm{He}, \mathrm{N}_{2}$, and $\mathrm{Ar}$, that are absorbed in polymers. Simultaneous three-channel real-time techniques for measuring the sorption content and diffusivity of gases emitted from polymers are developed after exposure to high pressure and the subsequent decompression of the corresponding gas. These techniques are based on the volumetric measurement of released gas combined with the capacitance measurement of the water content by both semicylindrical and coaxial-cylindrical electrodes. This minimizes the uncertainty due to the varying temperature and pressure of laboratory environments. The gas uptake and diffusivity are determined as a function of the exposed pressure and gas spices in nitrile butadiene rubber (NBR) and ethylene propylene diene monomer (EPDM) polymers. The pressure-dependent gas transport behaviors of four different gases are presented and compared with those obtained by different techniques. A linear correlation between the logarithmic diffusivity and kinetic diameter of molecules in the gas is found between the two polymers.
\end{abstract}

Keywords: polymer; gas permeation; diffusion; capacitance; kinetic diameter

\section{Introduction}

The permeability of a polymer is defined as the rate at which it is penetrated by various gases. The characteristic passage of gas through a polymer is affected by the solubility in the polymer, and gases pass through the polymer sheet by the process of diffusion. In other words, gas permeation is the passage of a permeant through a polymer material. The process of permeation involves the diffusion of molecules-i.e., the permeant-through a membrane or interface where the permeant will move from a high concentration to a low concentration across the interface. Permeation is extensively utilized for various applications, such as in the food packaging field, tires and fuel cells in automobiles, electrical insulating materials, the medical field for drug delivery, thermoplastic piping in gas transportation, and O-rings in high-pressure gas vessels [1-5]. Studying the permeability characterization of materials with different gases and under different environmental conditions is crucial in order to understand whether the corresponding material is adapted to the chosen gases. At the same time, the transport properties of gases to permeate the materials can be clarified with reliable measurement techniques.

Meanwhile, the gas permeation of a material can be measured by numerous methods that quantify the permeability of a material. These methods include manometric methods [6-8], constant-pressure methods [7], gravimetric techniques [9], magnetic suspension balance methods [10,11], gas chromatography [12], and computer simulation [13,14]. Most methods are time-consuming, requiring complicated processes and fine control. For instance, for polymers with a diffusivity in the order of $10^{-11} \mathrm{~m}^{2} / \mathrm{s}$ and with a thickness above $3 \mathrm{~mm}$, it takes at least a few days to reach the adsorption/desorption equilibrium 
and then complete the permeation measurement. Furthermore, the variation in both temperature and pressure across the days affects measurements of aspects such as the gas volume and then increases the uncertainty in the determination of permeation parameters. Thus, the instability due to temperature and pressure should be minimized to achieve precise measurement and compensation.

Effective and real-time automatic measurements are required to overcome the limitations of methods and further enhance the reliability of the measurement of permeability characteristics. We sought to find an appropriate technique for determining the permeation properties of several gases dissolved in materials. Thus, we developed the volumetric analysis technique (VAT) in previous studies [15] and confirmed this by comparing the results obtained using VAT with those obtained using different methods, such as gas chromatography (GC) by thermal desorption analysis (TDA) and gravimetric measurement by electronic balance for same samples. The results were found to be consistent with each other. A more effective technique is to combine a volumetric measurement using a graduated cylinder and automatic capacitance measurement with electrodes through a frequency response analyzer interfaced with a PC. The developed technique reduces the uncertainty of permeation parameters due to the varying temperature and pressure of the laboratory environment. The techniques were applied to nitrile butadiene rubber (NBR) and ethylene propylene diene monomer (EPDM) polymers, which are used for gas sealing materials under high pressure. The solubility, diffusivity, and permeability of the four different gases in the two polymers were investigated as a function of the exposed pressure and compared with those determined by different methods. The permeation characteristics obtained by this method were described. Another motivation of our research was that the polymer materials can be applicable for various gas sealing requirements under a high pressure. The diffusivity in the NBR and EPDM polymers can be interpreted in terms of the kinetic diameter of molecules in the employed gases.

\section{Experimental Aspects}

\section{Sample Preparation and Gas Exposure Conditions}

The compositions and densities of the NBR and EPDM polymer specimens used in this study have already been listed in previous literature $[15,16]$. NBR samples with two different thicknesses and EPDM samples with different shapes/dimensions were used: cylindrical-shaped NBR samples with a radius of $7.0 \mathrm{~mm}$ and thicknesses of $1.1 \mathrm{~mm}$ and $2.2 \mathrm{~mm}$ were prepared. Cylindrical-shaped EPDM samples with a radius of $7.0 \mathrm{~mm}$ and thicknesses of $1.4 \mathrm{~mm}$ and $2.5 \mathrm{~mm}$ as well as spherical-shaped EPDM with a radius of $4.9 \mathrm{~mm}$ were also prepared.

A SUS 316 chamber with an inner diameter of $50 \mathrm{~mm}$ and height of $90 \mathrm{~mm}$ was used for gas exposure to high pressure at room temperature and a specified pressure. The chamber was purged three times with the corresponding gas of $1 \mathrm{MPa}-3 \mathrm{MPa}$ depending on the pressure before the gas exposure. We exposed the specimen to the gas for $24 \mathrm{~h}$ in a pressure range from $1.5 \mathrm{MPa}$ to $10 \mathrm{MPa}$. Gas charging for $24 \mathrm{~h}$ is sufficient to attain the equilibrium state for gas sorption, except for $\mathrm{N}_{2}$ gas exposure. $\mathrm{N}_{2}$ gas charging for $48 \mathrm{~h}$ is needed to attain the equilibrium state for $\mathrm{N}_{2}$ sorption because of its slow diffusion rate. After exposure to gas, the valve was opened and the gas in the chamber was released. After decompression, the elapsed time was recorded from the moment $(t=0)$ at which the highpressure gas in the chamber was reduced to atmospheric pressure when the time was set to zero. Since the specimen was loaded in the graduated cylinder after decompression, it took approximately 5-10 min to start the measurement. The gas content emitted for the inevitable time lag could be measured later by offset determination via the simulation.

\section{Two Types of Capacitor Electrodes to Measure the Water Level}

We employed two types of electrodes to measure the capacitance corresponding to the water content in the acrylic tube (graduated cylinder). A semi-cylindrical capacitor and coaxial-cylindrical capacitor electrodes were fabricated and attached to the outer wall 
of the graduated cylinder. The capacitance was measured at $1 \mathrm{MHz}$ with two electrodes by a frequency response analyzer (VSP 300) with a general-purpose interface bus (GPIB) connected to a PC.

\subsection{Semi-Cylindrical Capacitor Electrode}

The capacitive sensor fabricated with semi-cylindrical electrodes mounted outside of an acrylic tube is shown in Figure 1a. An acrylic tube surrounded by two semi-cylindrical electrodes is filled with water gas. The electrode attached to the outer wall of the acrylic tube is made of copper cylinder with a thickness of $1 \mathrm{~mm}$. The capacitance of the sensor depends on the dielectric permittivity of the medium existing between the electrodes. The dielectric permittivity of water is 78.4 times larger than that of gas inside the graduated cylinder. Thus, the position shift of the water level in the two electrodes leads to a change in the capacitance.

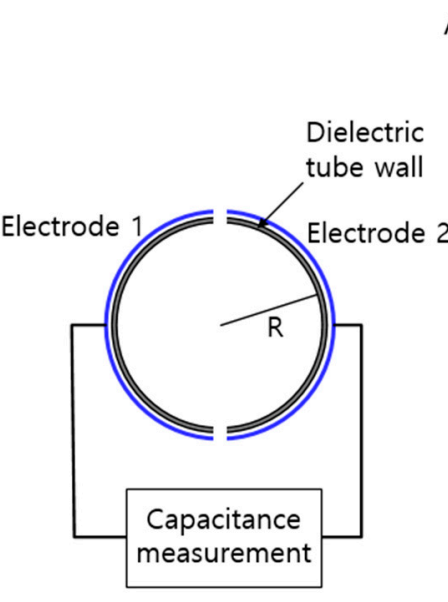

Top view

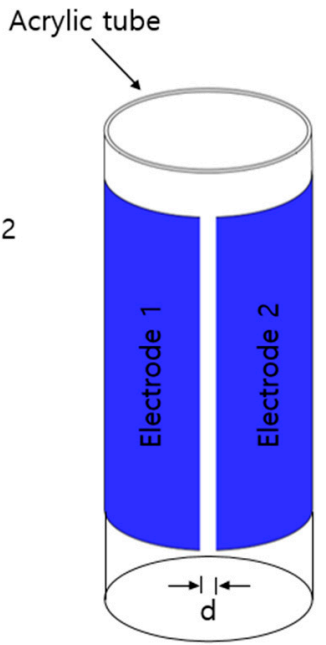

Side view

(a)

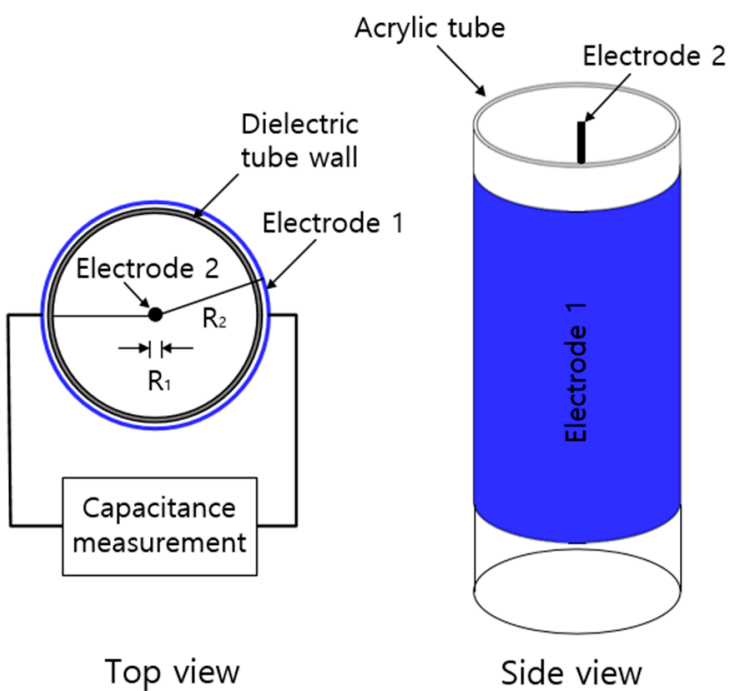

(b)

Figure 1. (a) Configuration of the semi-cylindrical capacitor electrode, indicated in blue. (b) Configuration of the coaxial-cylindrical capacitor electrode. 
The actual capacitance $\left(C_{a}\right)$ due to water gas is connected in series with the capacitance $\left(C_{t w}\right)$ of the acrylic dielectric tube wall. The total capacitance $\left(C_{t}\right)$ between the semicylindrical electrodes can be expressed as:

$$
C_{t}=\frac{C_{a} C_{t w}}{C_{a}+C_{t w}}
$$

The actual permittivity $\left(\varepsilon_{a}\right)$ of both the water and gas inside the cylinder, depending on the volume fraction of the two media, is given by:

$$
\varepsilon_{a}=\frac{V_{w} \varepsilon_{w}+V_{0} \varepsilon_{0}}{V_{t}}
$$

where $V_{w}$ is the water volume in the cylinder, $\varepsilon_{w}$ is the dielectric permittivity of water, $V_{0}$ is the gas volume in the cylinder, $\varepsilon_{0}$ is the dielectric permittivity of gas, and $V_{t}$ is the total volume.

The actual capacitance with two semi-cylindrical electrodes of the same size is calculated as [17]:

$$
C_{a}=\sum_{i=0}^{n} 2 \varepsilon^{*}{ }_{0} \varepsilon_{a} A \times\left[\frac{1}{d+(i-1) \Delta d}\right]+\frac{\varepsilon_{0} \varepsilon_{a} A}{2 R}
$$

where $A$ is the area of the electrode, $\varepsilon^{*}{ }_{0}$ is the dielectric permittivity of free space, $d$ is the distance between the electrodes, $R$ is the radius of the acrylic tube, and $\Delta d$ is an increment distance between semi-cylindrical concave electrodes. In this work, the values in Equation (3) are constant except for $\varepsilon_{a}$. The capacitance values with respect to the water content are obtained by a combination of Equations (1)-(3). We measured the change in actual capacitance $\left(C_{a}\right)$ by the change in $\varepsilon_{a}$ arising from the changing water level in the graduated cylinder. Therefore, the changing water level corresponding to the change capacitance is determined with the precalibration equation between the capacitance and water level, which will be presented in the following chapter.

\subsection{Coaxial-Cylindrical Capacitor Electrode}

Another capacitive sensor is designed with coaxial-cylindrical electrodes mounted at the center and outside of an acrylic tube, as shown in Figure 1b. The water gas in the acrylic tube is filled between two coaxial electrodes. The change in capacitance, $\Delta C$, with respect to the water level, $h$, and remaining height, $L-h$, in the cylinder filled with gas is given by [18]:

$$
\Delta C=\frac{2 \pi \varepsilon_{0}\left(\varepsilon_{w} h+\varepsilon_{g}(L-h)\right)}{\ln \left(\frac{R_{2}}{R_{1}}\right)}=\frac{2 \pi \varepsilon_{0}\left(\varepsilon_{w}-\varepsilon_{g}\right) h}{\ln \left(\frac{R_{2}}{R_{1}}\right)}+\frac{2 \pi \varepsilon_{0} \varepsilon_{g} L}{\ln \left(\frac{R_{2}}{R_{1}}\right)}
$$

where $h$ is the water level, $L$ is the length of the cylindrical capacitor, $R_{1}$ is the radius of the solid cylindrical conductor (electrode 2) made of thin copper wire, and $R_{2}$ is the inner radius of the coaxial cylindrical shell (electrode 1) made of copper plate. $\varepsilon_{0}, \varepsilon_{w}$, and $\varepsilon_{g}$ are the permittivity of free space, water, and gas, respectively.

For a fixed configuration of the coaxial cylindrical electrode, Equation (4) indicates that $\Delta C$ is linearly related to the change in the water level, $h$. Similar to the semi-cylindrical electrode, we thus determined the water level by measuring the change in capacitance with a precalibration equation.

\section{Volumetric Analysis Measurement System}

\subsection{Volumetric Measurement of Emitted Gas}

Figure 2 shows a three-channel volumetric measurement system with three graduated cylinders and three electrodes to measure the released gas in real time. After exposure to the high-pressure chamber and subsequent decompression, the specimen is loaded into the gas space of a graduated cylinder. Three parallel standing graduated cylinders 
partially immersed in each water container collect and measure the gas released from the specimen. The semi-cylindrical and coaxial-cylindrical electrodes, connected in parallel to the responding capacitance measurement channel of the frequency response analyzer, are mounted outside of acrylic tubes in the left and right cylinders and center cylinder. The precise frequency response analyzer (FRA, VSP 300) with an excellent performance is a general purpose interface bus (GPIB) interfaced with a programmed PC with autosensing and autocontrol functions for the temperature and pressure. The FRA GPIB interfaced with the PC at three channels is employed for automatic real-time capacitance measurement with both semi-cylindrical and coaxial-cylindrical electrodes, as shown in Figure 2. The temperature and pressure measured near the sample are automatically applied for the calculation of the gas uptake.

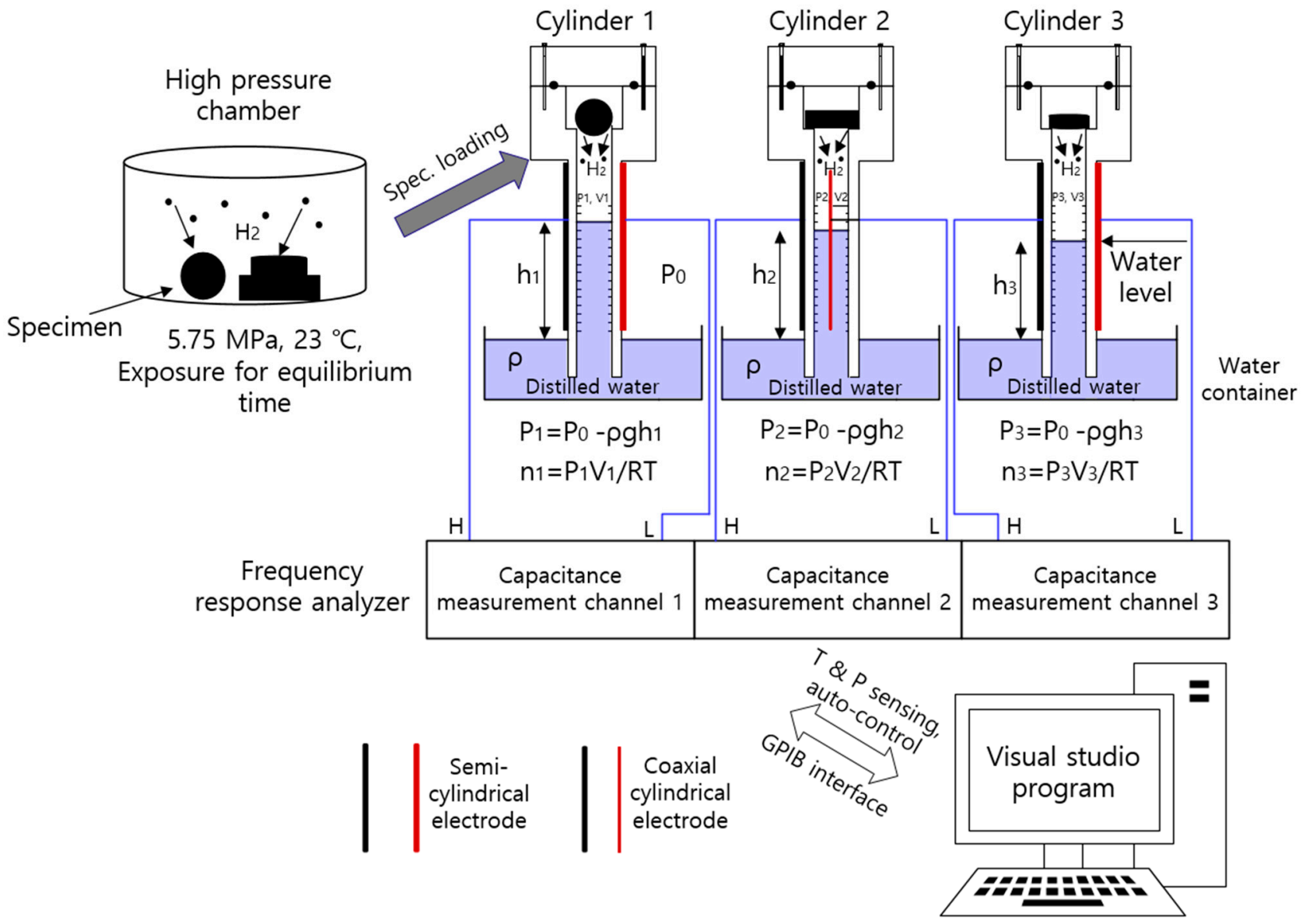

Figure 2. Schematic diagram of the three-channel volumetric measurement system in which three cylinders are standing. The blue part indicates the distilled water filling the water containers and cylinders. A frequency response analyzer GPIB interfaced with a PC at three channels is employed for automatic real-time capacitance measurement with both semi-cylindrical and coaxial-cylindrical electrodes.

The pressures $\left(P_{1}, P_{2}\right.$, and $\left.P_{3}\right)$ inside each graduated cylinder for the three channels are expressed as [15]:

$$
P_{1}=P_{o}-\rho g h_{1}, P_{2}=P_{o}-\rho g h_{2}, P_{3}=P_{o}-\rho g h_{3}
$$

where $P_{o}$ is the outside atmospheric pressure of the cylinder, $\rho$ is the density of distilled water in the water container, and $g$ is gravity. $h_{1}, h_{2}$, and $h_{3}$ are the heights of the distilled water level inside the corresponding graduated cylinder measured from the water level in the water container of channel 1 , channel 2 , and channel 3 , respectively. $V_{1}, V_{2}$, and $V_{3}$ are 
the gas volumes inside the corresponding graduated cylinder filled with gas. As shown in Figure 2, the gas inside the cylinder is governed by the ideal gas equation, $P V=n R T$, and $R$ is the gas constant with $8.20544 \times 10^{-5} \mathrm{~m}^{3} \cdot \mathrm{atm} /(\mathrm{mol} \cdot \mathrm{K})$.

The total number of moles $\left(n_{1}, n_{2}\right.$ and $\left.n_{3}\right)$ of gas inside the corresponding cylinder for the three channels is expressed at specified $P$ and $T$ as follows:

$n_{1}=n_{1,0}+\Delta n_{1}=\frac{\left(P_{o}-\rho g h_{1}\right) V_{1}}{R T}, n_{2}=n_{2,0}+\Delta n_{2}=\frac{\left(P_{o}-\rho g h_{2}\right) V_{2}}{R T}, n_{3}=n_{3,0}+\Delta n_{3}=\frac{\left(P_{o}-\rho g h_{3}\right) V_{3}}{R T}$

where $n_{1,0}, n_{2,0}$, and $n_{3,0}$ are the initial number of moles of air already in cylinder 1 , cylinder 2 , and cylinder 3 , respectively, before the gas emission. The gas released from the specimen after decompression lowers the water level of the cylinder. Thus, the increased number of moles $\left(\Delta n_{1}, \Delta n_{2}\right.$, and $\left.\Delta n_{3}\right)$ in each cylinder from emitted gas after decompression is obtained by measuring the increase in volume $\left(\Delta V_{1}, \Delta V_{2}\right.$, and $\left.\Delta V_{3}\right)$ in each graduated cylinder, with the lowering of the water level as follows:

$$
\Delta n_{1}=\frac{\left(P_{o}-\rho g h_{1}\right) \Delta V_{1}}{R T}, \Delta n_{2}=\frac{\left(P_{o}-\rho g h_{2}\right) \Delta V_{2}}{R T}, \Delta n_{3}=\frac{\left(P_{o}-\rho g h_{3}\right) \Delta V_{3}}{R T}
$$

The increased number of moles in each channel is converted to the corresponding mass concentration $\left[C_{1}(t), C_{2}(t)\right.$, and $\left.C_{3}(t)\right]$ of gas emitted from the rubber sample as follows:

$$
\begin{aligned}
& C_{1}(t)[\mathrm{wt} \cdot \mathrm{ppm}]=\Delta n_{1}[\mathrm{~mol}] \times \frac{m_{\text {gas }}\left[\frac{\mathrm{g}}{\mathrm{mol}}\right]}{m_{\text {sample }}[\mathrm{g}]} \times 10^{6} \\
& C_{2}(t)[\mathrm{wt} \cdot \mathrm{ppm}]=\Delta n_{2}[\mathrm{~mol}] \times \frac{m_{\text {gas }}\left[\frac{\mathrm{g}}{\mathrm{mol}}\right]}{m_{\text {sample }}[\mathrm{g}]} \times 10^{6} \\
& C_{3}(t)[\mathrm{wt} \cdot \mathrm{ppm}]=\Delta n_{3}[\mathrm{~mol}] \times \frac{m_{\text {gas }}\left[\frac{\mathrm{g}}{\mathrm{mol}}\right]}{m_{\text {sample }}[\mathrm{g}]} \times 10^{6}
\end{aligned}
$$

where $m_{\text {gas }}(\mathrm{g} / \mathrm{mol})$ is the molar mass of the gas investigated. For example, for $\mathrm{H}_{2}$ gas, $m_{H 2 \mathrm{gas}}$ is $2.016 \mathrm{~g} / \mathrm{mol} . m_{\text {sample }}$ is the mass of the specimen. By measuring the change in the water level $(\Delta V)$, we obtained an increased number of moles and thus transformed the mass concentration of the emitted gas. Therefore, the time-dependent mass concentration by released gas can be obtained by measuring the water level change, $\Delta V$, versus the time elapsed since decompression. The water level data were transformed from the capacitance by the precalibration data of the polynomial form between the capacitance and the position of the water level.

\subsection{Time-Dependent Emitted Gas Concentration versus Specimen Shape}

The adsorption of gas under high pressure causes the release of gas dissolved in rubber after decompression to atmospheric pressure. Assuming that the adsorption and desorption of gas are diffusion-controlled processes, the emitted gas concentration $C_{E}(t)$ in the desorption process is expressed as $[19,20]$ :

$$
C_{E}(t)=C_{\infty}\left[1-\frac{6}{\pi^{2}} \sum_{n=1}^{\infty} \frac{1}{n^{2}} \exp \left(-\frac{D n^{2} \pi^{2} t}{a^{2}}\right)\right]
$$

Equation (9) is the solution to Fick's second law of diffusion for a spherical sample with an initially constant uniform gas concentration and constant concentration at the spherical surface. $C_{\infty}$ is the saturated gas mass for an infinitely long time-i.e., the total emitted mass concentration or gas uptake in the adsorption process. $D$ is the diffusion coefficient of desorption. $a$ is the radius of the spherical rubber $[19,20]$. 
Similarly, the emitted gas content $C_{E}(t)$ for a cylindrical specimen is expressed under the boundary condition-i.e., a uniform gas concentration is initially maintained and the cylindrical surfaces are kept at a constant concentration $[19,20]$ :

$$
C_{E}(t) / C_{\infty}=1-\frac{32}{\pi^{2}} \times\left[\sum_{n=0}^{\infty} \frac{\exp \left\{\frac{-(2 n+1)^{2} \pi^{2} D_{s} t}{l^{2}}\right\}}{(2 n+1)^{2}}\right] \times\left[\sum_{n=1}^{\infty} \frac{\exp \left\{-\frac{D_{s} \beta_{n}^{2} t}{\rho^{2}}\right\}}{\beta_{n}^{2}}\right]
$$

In Equation (10), $l$ is the thickness of the cylindrical rubber sample, $\rho$ is the radius, and $\beta_{n}$ is the root of the zero-order Bessel function. To analyze the mass concentration data, we used a diffusion analysis program developed using Visual Studio to calculate $D$ and $C_{\infty}$ in Equations (9) and (10) based on least-squares regression [15,21].

\subsection{Diffusion Parameter Analysis through Programmed Capacitance Measurement}

The gas emitted from the specimen lowers the water level, and then the water level decreases as the elapsed time increases. Using programmed capacitor measurements with electrodes and diffusion analysis programs, the diffusion parameters for specimens can be determined. Figure $3 \mathrm{a}-\mathrm{c}$ shows the processes used for acquiring the diffusion parameter in NBR cylindrical rubber by coaxial-cylindrical electrodes as follows:

(a) To obtain the precalibration data, the user measures the water level versus the capacitance at the corresponding channel with decreasing water levels. Then, the 2nd polynomial equation related to the position of the water level and capacitance is obtained by quadratic regression, as shown in Figure 3a. The 2nd polynomial equation originates from Equation (4). The position of the water level is measured by a digital camera.

(b) According to the precalibration data, the capacitance is transformed to the water level, as shown in Figure 3b. The black and blue squares correspond to the capacitance and position of the water level, respectively, versus the time elapsed.

(c) Last, the diffusion parameters $D$ and $C_{\infty}$ are determined using a diffusion analysis program by applying Equation (10) based on least-squares regression, as shown in Figure $3 c$.

Figure 4 shows the sequence used for obtaining the diffusion parameter manually by a digital camera for the same NBR as Figure 3. Figure 4a shows the water level measured directly by a digital camera without precalibration, and Figure $4 \mathrm{~b}$ shows the water level as a function of time transformed to the mass concentration, resulting in diffusion parameters $D$ and $C_{\infty}$ determined using a diffusion analysis program. The two results in Figures 3 and 4 are consistent with each other.

Figure 5 represents the sequence of acquiring diffusion parameters for EPDM cylindrical rubber by employing semi-cylindrical electrodes. Figure 5 a represents precalibration data expressed as the 2nd polynomial equation between the water level and capacitance by quadratic regression, which comes from Equations (1)-(3). Figure 5 b shows the water level transformed from the capacitance, where the black and blue squares correspond to the capacitance and transformed water level, respectively, versus time. Figure $5 c$ shows diffusion parameters $D$ and $C_{\infty}$, which are determined using a diffusion analysis program according to Equation (10). 

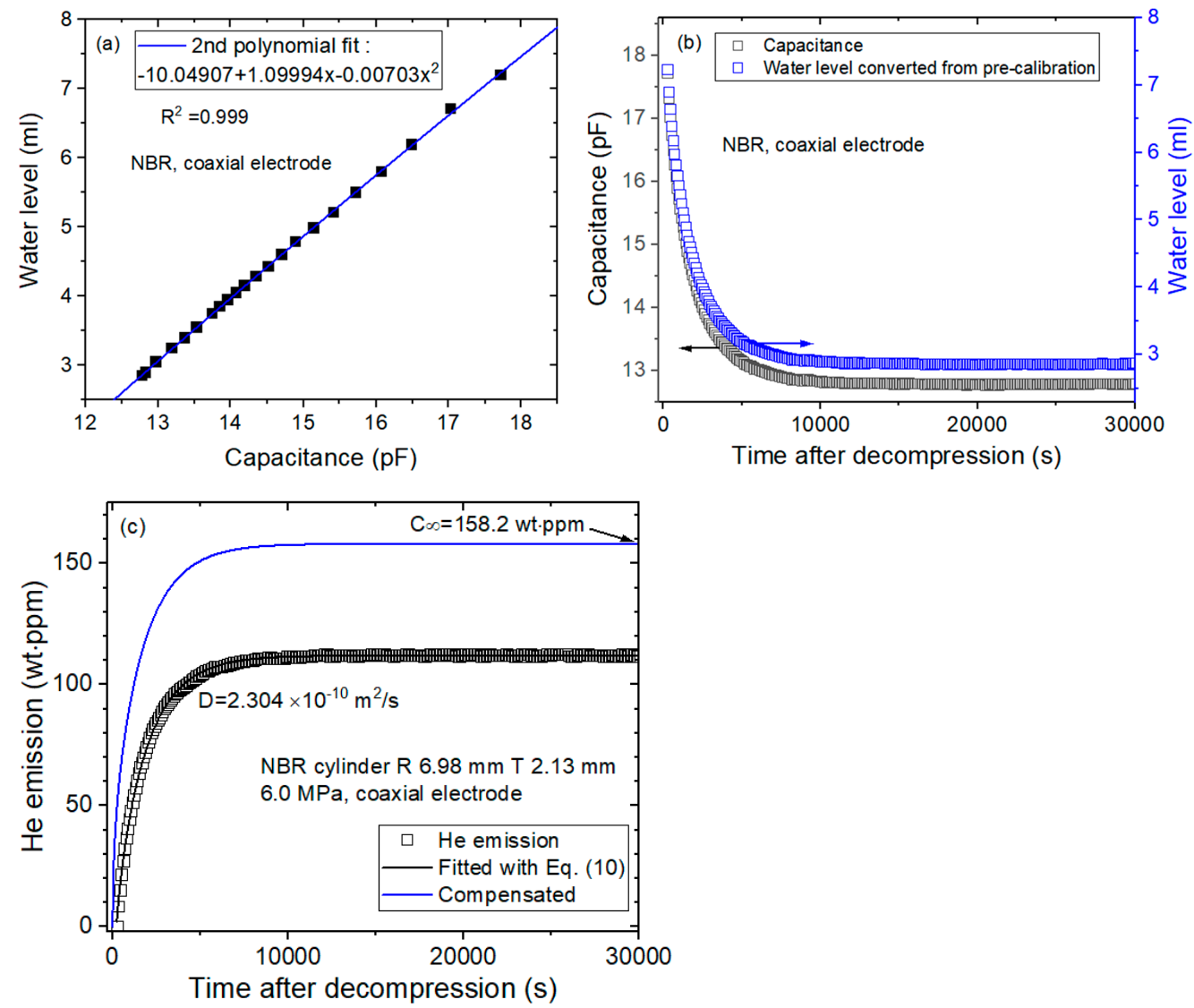

Figure 3. A sequence acquiring diffusion parameters measured for a NBR cylindrical rubber by employing coaxial-cylindrical electrodes in a frequency response analyzer. (a) Precalibration data expressed as a 2nd polynomial equation between the water level and capacitance by quadratic regression, (b) water level transferred from the capacitance with black and blue squares corresponding to the capacitance and transformed water level, respectively, versus time and (c) diffusion parameters $D$ and $C_{\infty}$ determined using a diffusion analysis program by application of Equation (10). The blue line is the total compensated emission curve restoring the missing content due to the lag time.
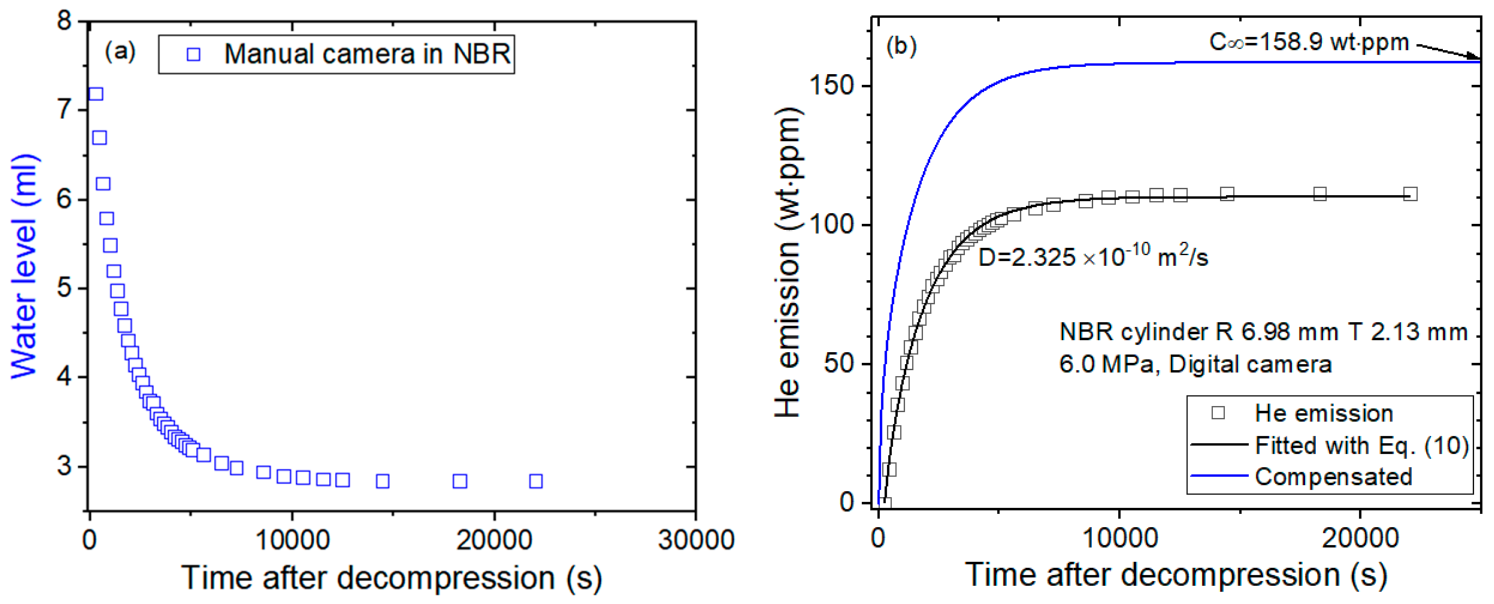

Figure 4. A sequence acquiring the diffusion parameter in NBR cylindrical rubber by employing a digital camera without precalibration. (a) Water level versus time after decompression and (b) diffusion parameters $D$ and $C_{\infty}$ determined using a diffusion analysis program. The blue line is the total compensated emission curve restoring the missing content due to the lag time. 

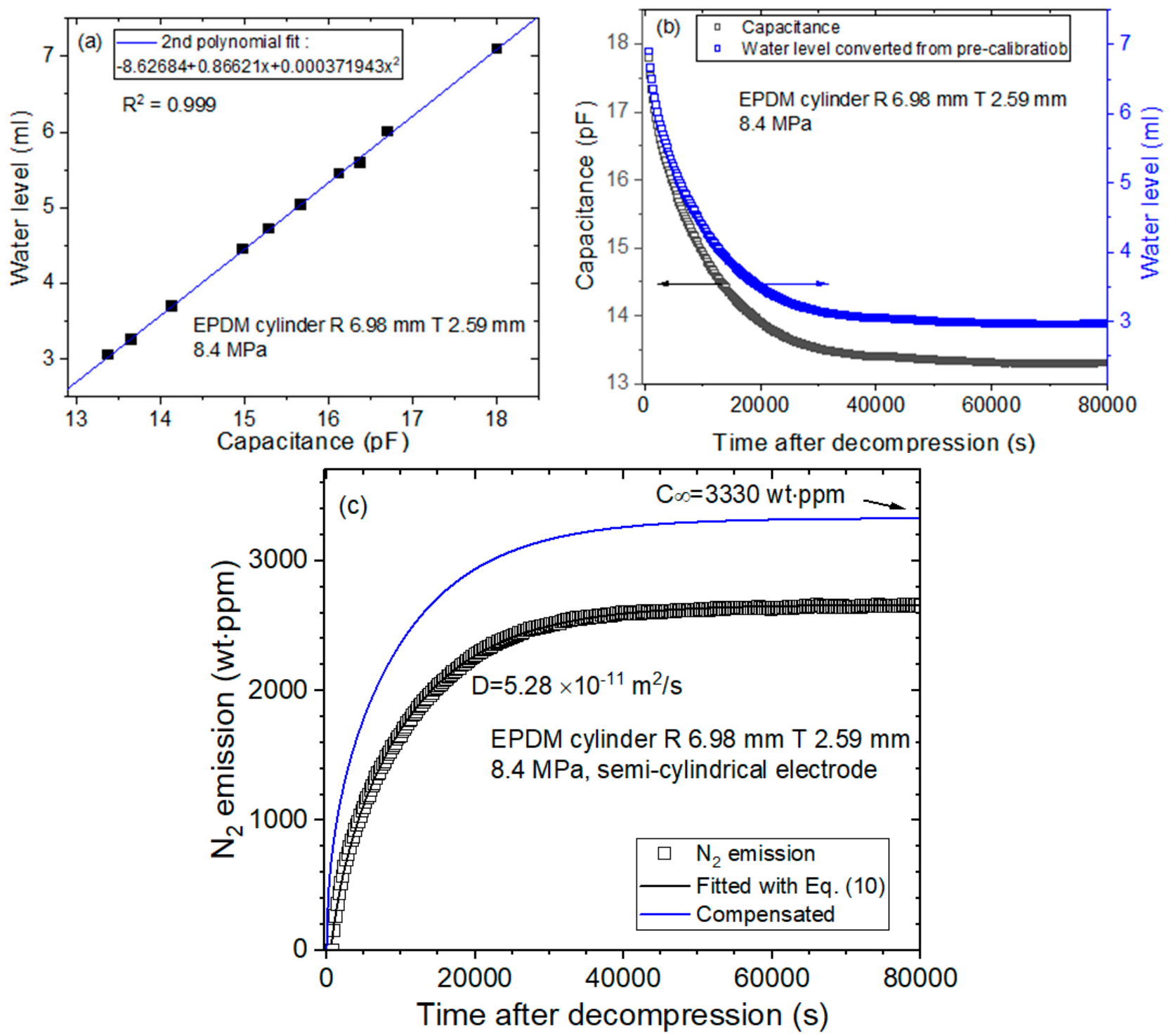

Figure 5. A sequence acquiring diffusion parameters measured for EPDM cylindrical rubber by employing semi-cylindrical capacitor electrodes in a frequency response analyzer. (a) Precalibration data expressed as a 2nd polynomial equation between the water level and capacitance by quadratic regression; (b) water level transformed from the capacitance, where black and blue squares correspond to the capacitance and transformed water level, respectively, versus elapsed time; and (c) diffusion parameters $D$ and $C_{\infty}$ determined using a diffusion analysis program by the application of Equation (10). The blue line is the total compensated emission curve restoring the missing content due to the lag time.

Figure 6 shows the sequence used for obtaining the diffusion parameter measured manually by a digital camera for the same EPDM as that shown in Figure 5. Figure 6a shows the water level measured directly by a digital camera, and Figure $6 \mathrm{~b}$ shows the water level as a function of time transformed to the mass concentration, resulting in diffusion parameters $D$ and $C_{\infty}$ determined using a diffusion analysis program. The two results in Figures 5 and 6 are consistent with each other. 

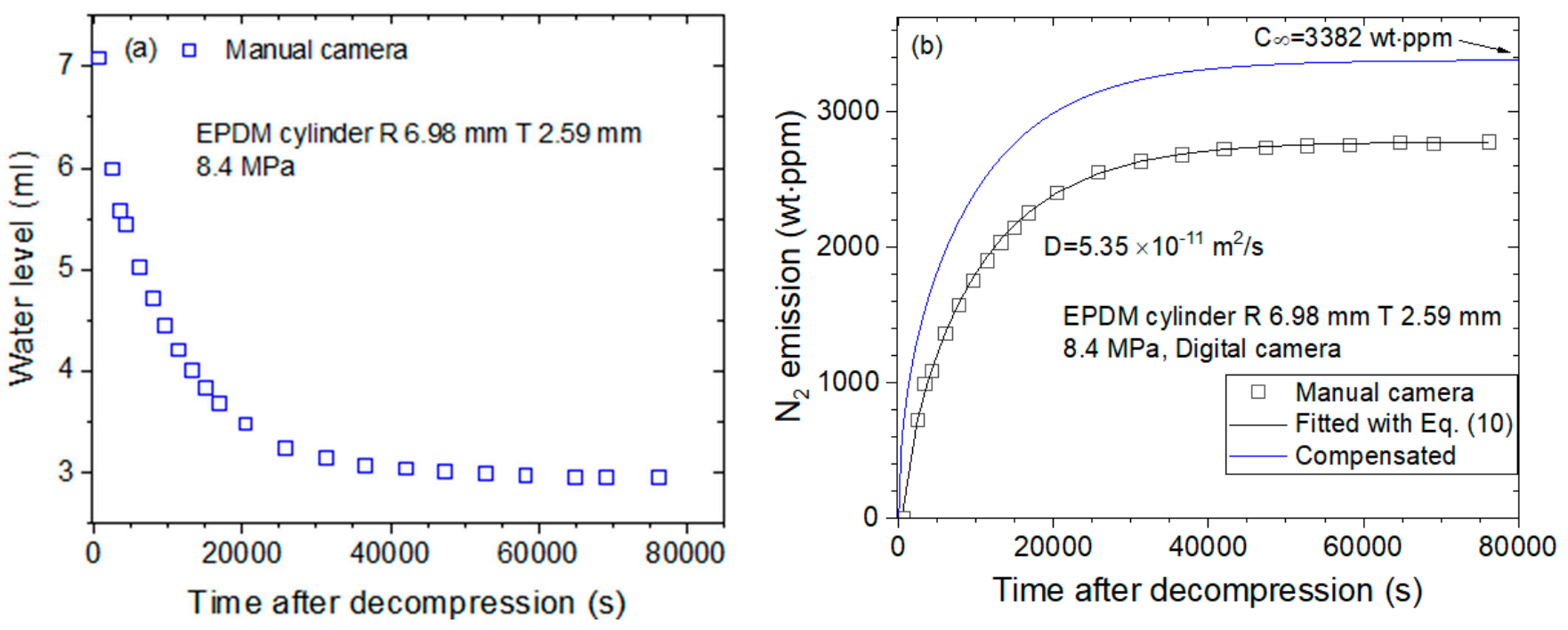

Figure 6. Sequence of acquiring the diffusion parameter in EPDM cylindrical rubber by employing a digital camera without precalibration. (a) Water level versus time after decompression and (b) diffusion parameters $D$ and $C_{\infty}$ determined using a diffusion analysis program. The blue line is the total compensated emission curve restoring the missing content due to the lag time.

\section{Results and Discussion}

\subsection{Stability Test of the Volumetric Measurement System}

The volume and number of moles of gas in the graduated cylinder are directly affected by both the temperature and pressure in the laboratory environment. Therefore, before measuring the main diffusion properties, the stability of the volumetric measurement system should be improved by applying variations in both the temperature and pressure during long-term measurement to calculations using Equations (6) and (7). Figure 7 shows the stability measurements performed for three days, in which the temperature (top of Figure 7) and pressure (middle of Figure 7) were maintained within $24.0 \pm 0.5{ }^{\circ} \mathrm{C}$ and $997.5 \pm 3.5 \mathrm{hPa}$, respectively. The bottom of Figure 7 represents the stability test with (closed circle) and without (open circle) the application of variation in both the temperature and pressure to Equations (6) and (7).

The change in the mass concentration due to correction for the changes in temperature and pressure over three days is within $4 \mathrm{wt} \cdot \mathrm{ppm}$, which is comparable with $7 \mathrm{wt} \cdot \mathrm{ppm}$ in the case that does not consider the variation in temperature and pressure. The system stability is improved by removing the variation in both the temperature and pressure, which are included as uncertainty factors in permeation parameter determination.

\subsection{Pressure Dependence on the Permeation Parameter}

Figures 8 and 9 show the permeation parameters versus exposed pressure in NBR and EPDM, respectively, for four different gases with coaxial-cylindrical or semi-cylindrical electrodes at three channels. The diffusion parameters $C_{\infty}$ and $D$ are determined using a diffusion analysis program by the application of Equations (9) and (10) based on leastsquares regression. The standard deviation between the experimental data and the diffusion model was within $3 \%$ for both rubbers. 

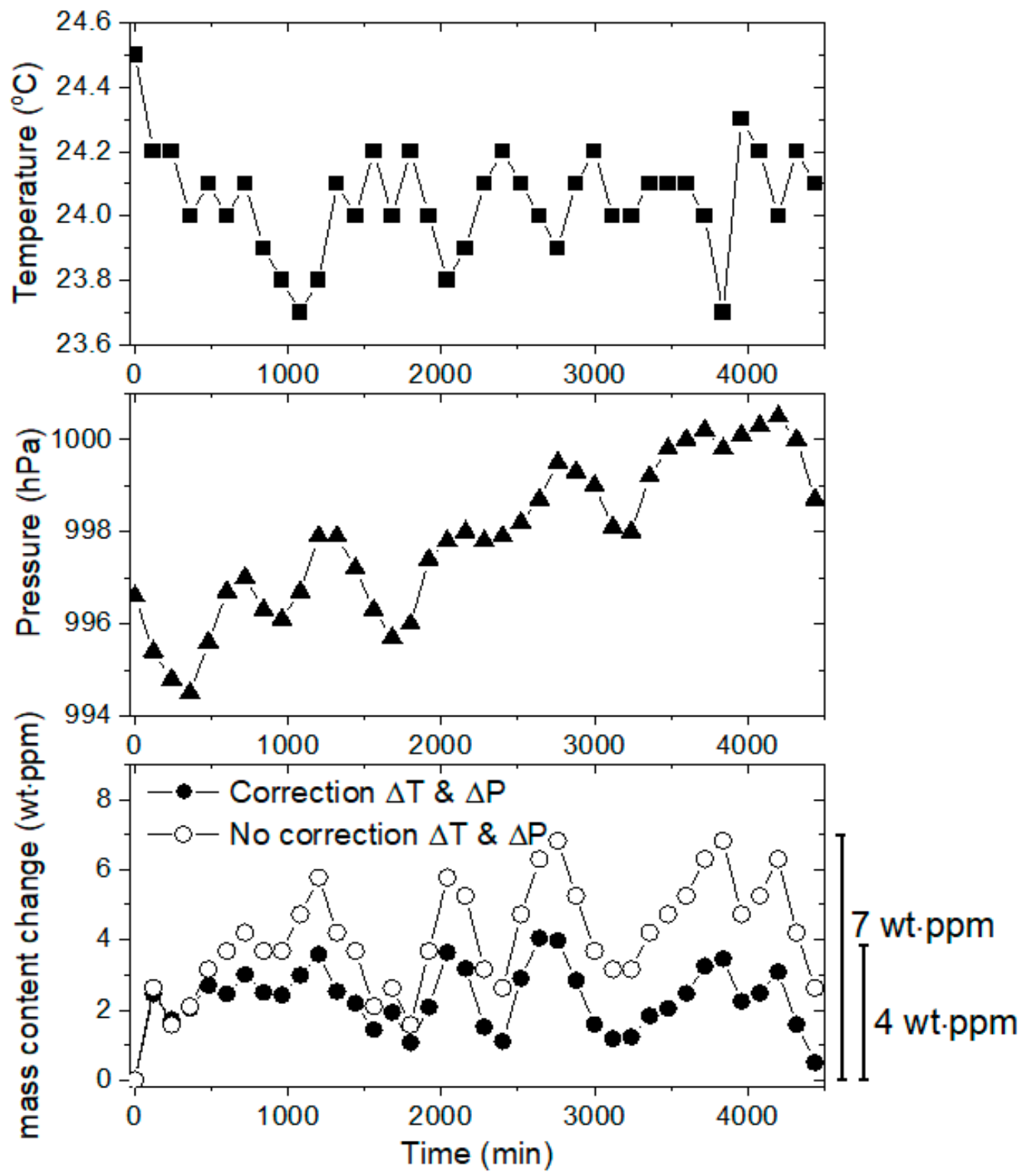

Figure 7. Stability for volumetric measurement with variations in the temperature and pressure over three days. 
(a)

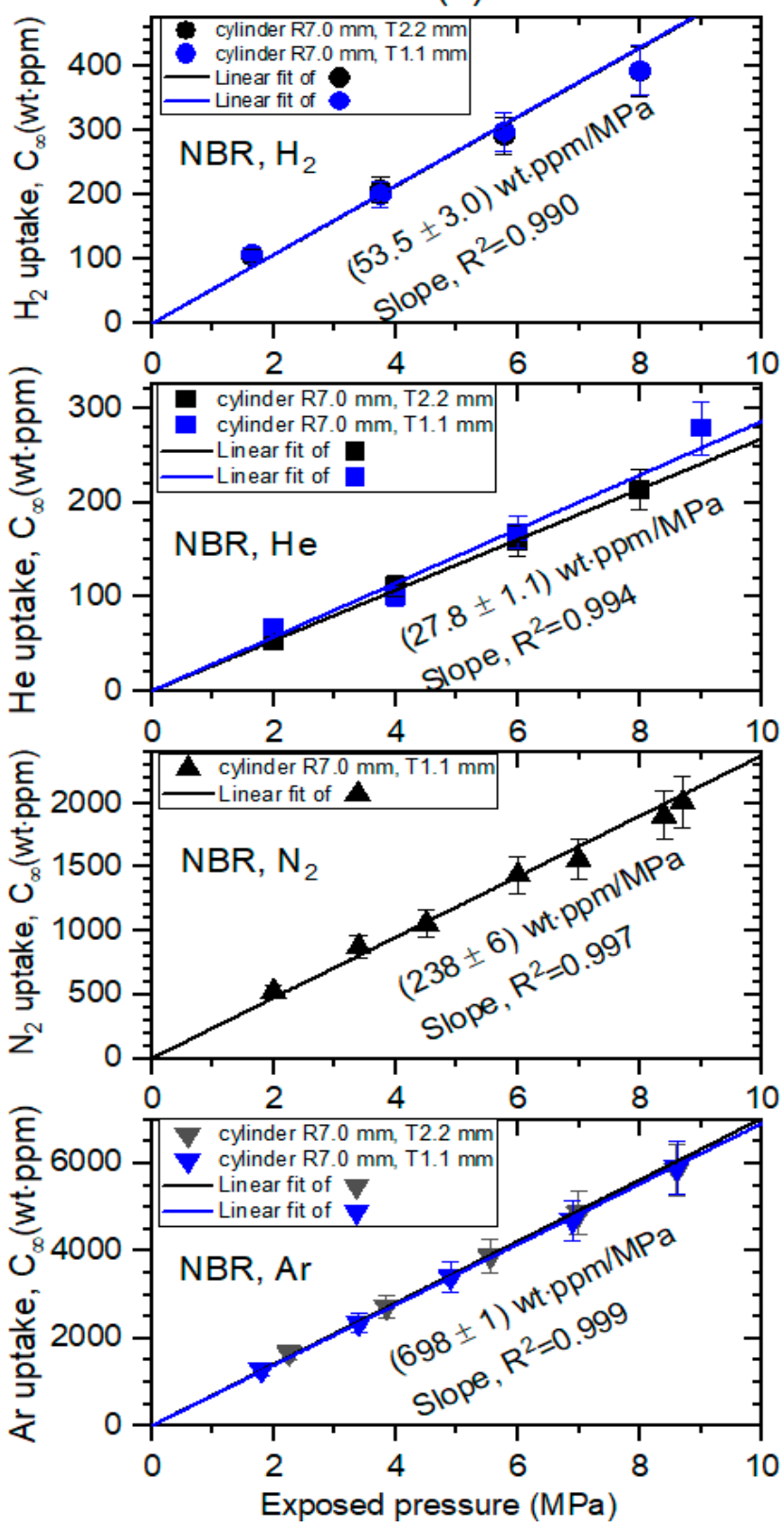

(b)
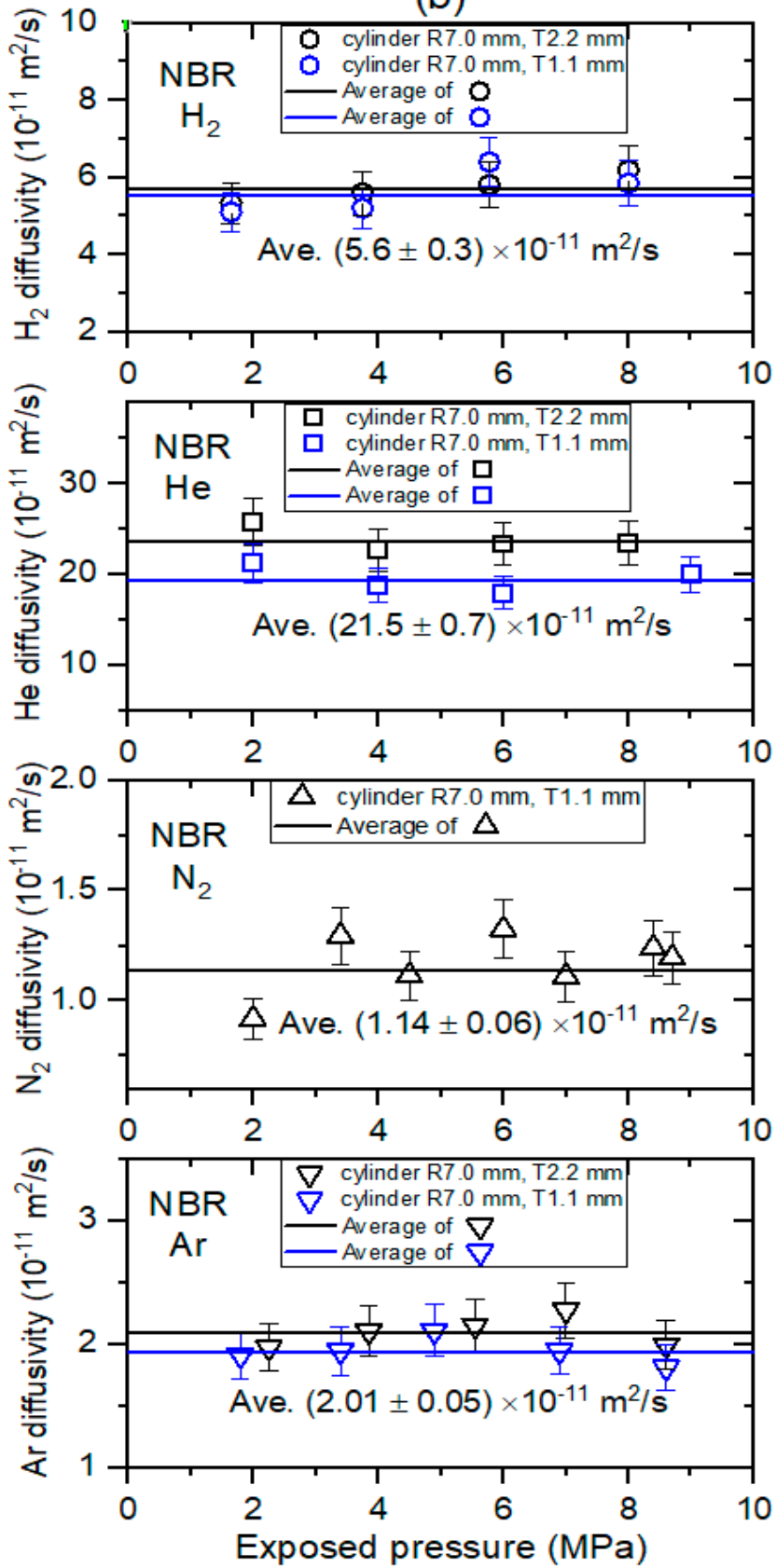

Figure 8. (a) Gas uptake $\left(C_{\infty}\right)$ and (b) diffusivity $(D)$ versus exposed pressure for four gases in cylindrical-shaped NBR with different thicknesses. R and T indicate the radius and thickness, respectively, of cylindrical-shaped NBR. 
(a)

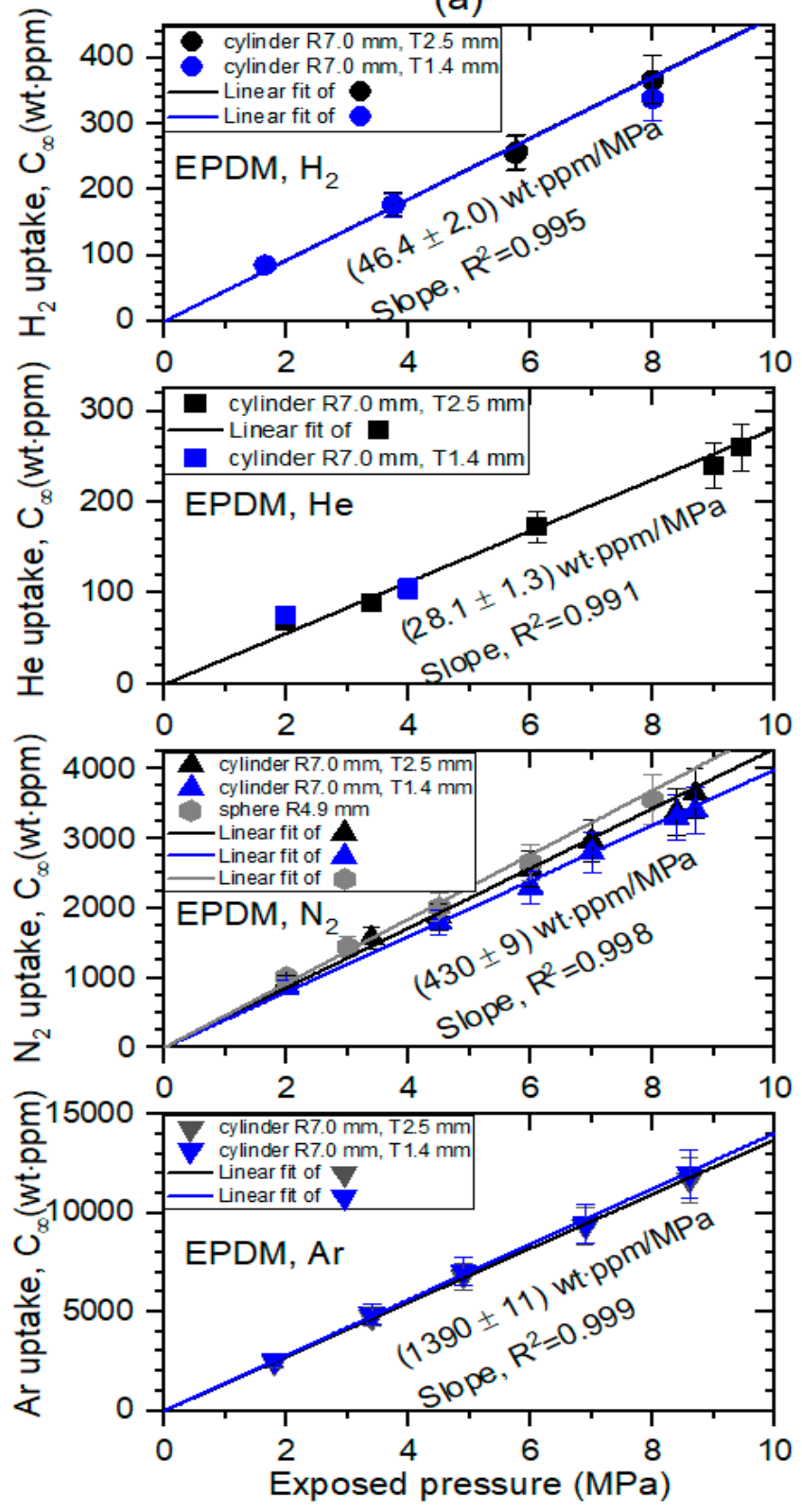

(b)
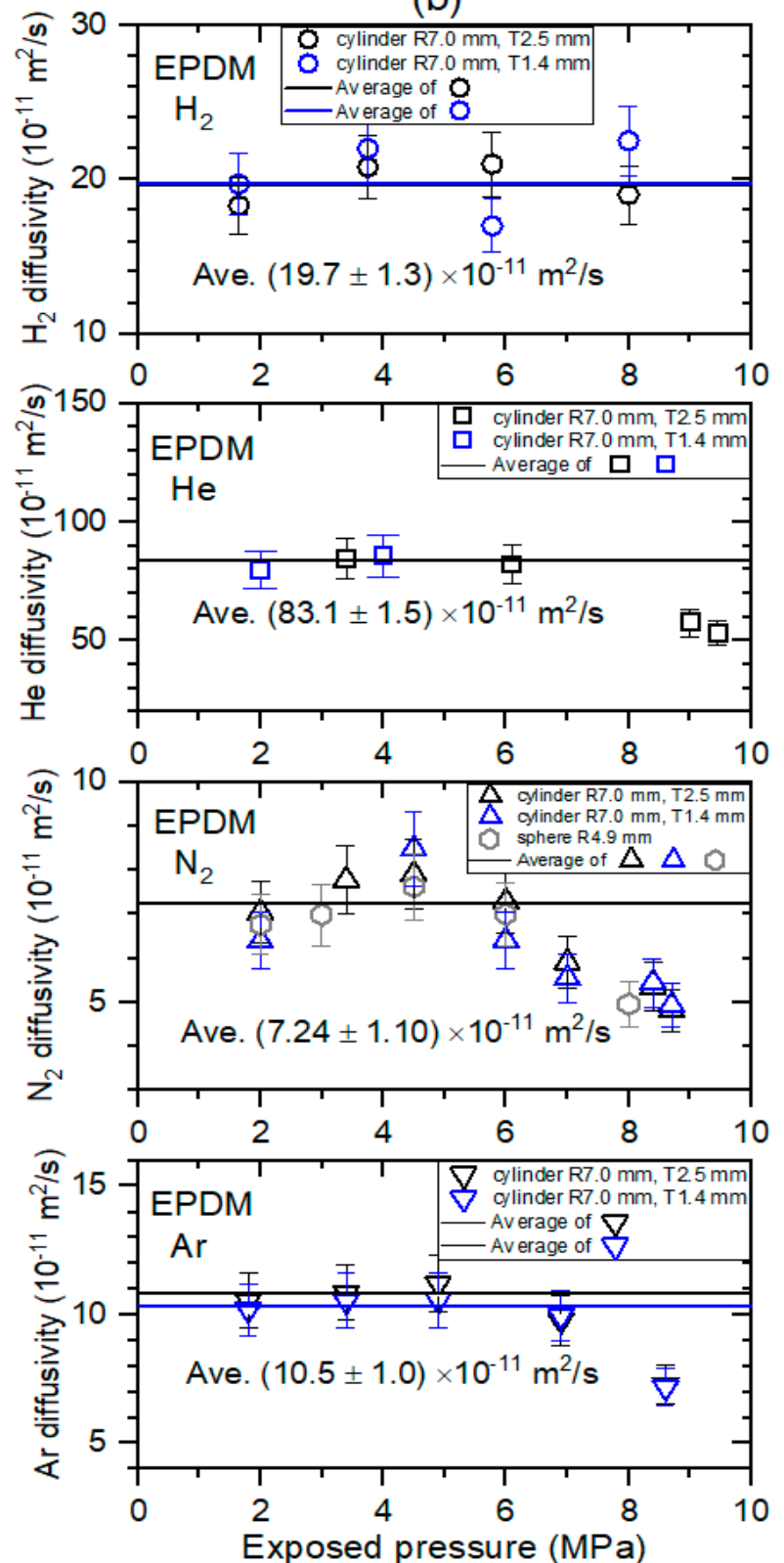

Figure 9. (a) Gas uptake $\left(C_{\infty}\right)$ and (b) diffusivity $(D)$ versus exposed pressure for four gases in cylindrical-shaped EPDM with different thicknesses and spherical-shaped EPDM. R indicates the radius of cylindrical-shaped and spherical-shaped EPDM. T indicates the thickness of the cylindricalshaped EPDM.

All the gas uptake follows Henry's law [22] up to $9 \mathrm{MPa}$ with a squared correlation coefficient $\mathrm{R}^{2}>0.990$, as indicated by the black and blue lines in Figure $8 \mathrm{a}$ for NBR, and black, blue, and gray lines in Figure 9a for EPDM. This implies that gas does not dissociate and penetrates into the specimen as a gas molecule. The slopes in the two specimens indicate Henry's law of solubility. As shown in Figure 8b, the diffusivity does not represent a distinct pressure dependency. Thus, we take the average diffusivity, as indicated by the black and blue horizontal lines. Meanwhile, Figure $9 \mathrm{~b}$ shows that the diffusivity decreases as the pressure increases above $6 \mathrm{MPa}$, except for $\mathrm{H}_{2}$ diffusivity. This may be ascribed to the bulk diffusion associated with the mean free path, which is normally observed for highpressure gas diffusion. The error bars indicate the relative expanded uncertainty of $10 \%$, as evaluated in previous research. At pressures below $6 \mathrm{MPa}$ in Figure 9b, we also take the 
average diffusivity, as indicated by black and blue horizontal lines. As shown in Figures 8 and 9, no dependence of the permeation parameters on the thickness in cylindrical-shaped NBR and EPDM was observed.

The solubility (S) is determined from the linear slope obtained in Figures 8a and 9a as follows:

$$
S\left[\frac{\mathrm{mol}}{\mathrm{m}^{3} \cdot \mathrm{MPa}}\right]=\frac{C_{\infty} \text { slope }\left[\frac{\mathrm{wt} \cdot \mathrm{ppm}}{\mathrm{MPa}}\right] 10^{6} \times d\left[\frac{\mathrm{g}}{\mathrm{m}^{3}}\right]}{m_{\mathrm{g}}\left[\frac{\mathrm{g}}{\mathrm{mol}}\right]}
$$

where $m_{g}$ is the molar mass of gas used, and $d$ is the density of the rubber. The permeabilities of the four gases in the NBR and EPDM polymers are obtained from the solubility and the average diffusivity by using the relation of $\mathrm{P}=\mathrm{D}_{\text {ave }} \mathrm{S}$. The permeation parameters for four gases in NBR and EPDM are summarized with those obtained by different methods in Table 1.

Table 1. Summary of the permeability properties for the parameters of four gases in NBR and EPDM.

\begin{tabular}{|c|c|c|c|c|c|c|c|c|c|c|c|c|}
\hline \multirow{2}{*}{ Specimen } & \multicolumn{4}{|c|}{ Solubility $\left(\mathrm{mol} / \mathrm{m}^{3} \cdot \mathrm{MPa}\right)$} & \multicolumn{4}{|c|}{ Diffusivity $\left(\times 10^{-11} \mathrm{~m}^{2} / \mathrm{s}\right)$} & \multicolumn{4}{|c|}{$\begin{array}{c}\text { Permeability } \\
\left(\mathrm{mol} / \mathrm{m} \cdot \mathrm{s} \cdot \mathrm{MPa}, \times 10^{-10}\right)\end{array}$} \\
\hline & $\mathbf{H}_{2}$ & $\mathrm{He}$ & $\mathbf{N}_{2}$ & Ar & $\mathbf{H}_{2}$ & $\mathrm{He}$ & $\mathbf{N}_{2}$ & Ar & $\mathbf{H}_{2}$ & $\mathrm{He}$ & $\mathbf{N}_{2}$ & Ar \\
\hline NBR & $\begin{array}{c}34.2 \\
(35.3)\end{array}$ & 8.96 & 11.0 & 22.5 & $\begin{array}{l}5.60 \\
(6.50)\end{array}$ & 21.5 & 1.14 & 2.01 & $\begin{array}{c}19.2 \\
(22.8)\end{array}$ & 19.3 & 1.25 & 4.53 \\
\hline EPDM & $\begin{array}{c}25.6 \\
(26.2) \\
{[23]}\end{array}$ & 7.79 & 17.0 & 38.6 & $\begin{array}{c}19.7 \\
(24.1) \\
{[23]}\end{array}$ & 83.1 & 7.24 & 10.5 & $\begin{array}{c}50.3 \\
(63.1) \\
{[23]}\end{array}$ & 64.8 & 12.3 & 40.4 \\
\hline
\end{tabular}

The values in parentheses were determined by the differential pressure method and thermal desorption analysis-gas chromatography [23] in the same specimen. The results obtained by different methods for $\mathrm{H}_{2}$ gas are consistent with those in the present experimental investigation within expanded uncertainty.

Differences in the permeation parameters were found for gases in both NBR and EPDM. The magnitudes of the diffusivity and permeability decrease in the orders $D_{\mathrm{He}}$ $>D_{\mathrm{H} 2}>D_{\mathrm{Ar}}>D_{\mathrm{N} 2}$ and $P_{\mathrm{He}}>P_{\mathrm{H} 2}>P_{\mathrm{Ar}}>P_{\mathrm{N} 2}$ in both NBR and EPDM. Although there are many factors affecting the permeation parameters of rubber, we focus on the molecule size in the gas. The size of the permeant molecule affects the diffusivity. As the effective size of the molecule increases, the diffusivity decreases. As expected for both NBR and EPDM (Figure 10a), we found a linear correlation with a squared correlation coefficient of $\mathrm{R}^{2}>0.90$ between the logarithmic diffusivity and kinetic diameter of the molecules in the gas, which is the size of the sphere of influence that can lead to a scattering event and is also related to the mean free path of molecules in a gas [24,25].

Figure 10a also displays different diffusivity values obtained at same kinetic diameter between NBR and EPDM polymer. For the case of NBR, the existence of a $-\mathrm{CN}$ polar group can make it possible to increase interchain interaction, leading to the tight packing of polymer chains. As a result, the available free volume decreases, and then NBR achieves a low diffusivity of gas molecules. In contrast, EPDM could have a large free volume due to the presence of norbornene, and thus it is not easy to have a tight packing of chains, resulting in the high diffusivity of gas. In addition, EPDM chains are expected to be more flexible than NBR since the chain mobility has also been known to be governed by the chain packing characteristics. 
(b)
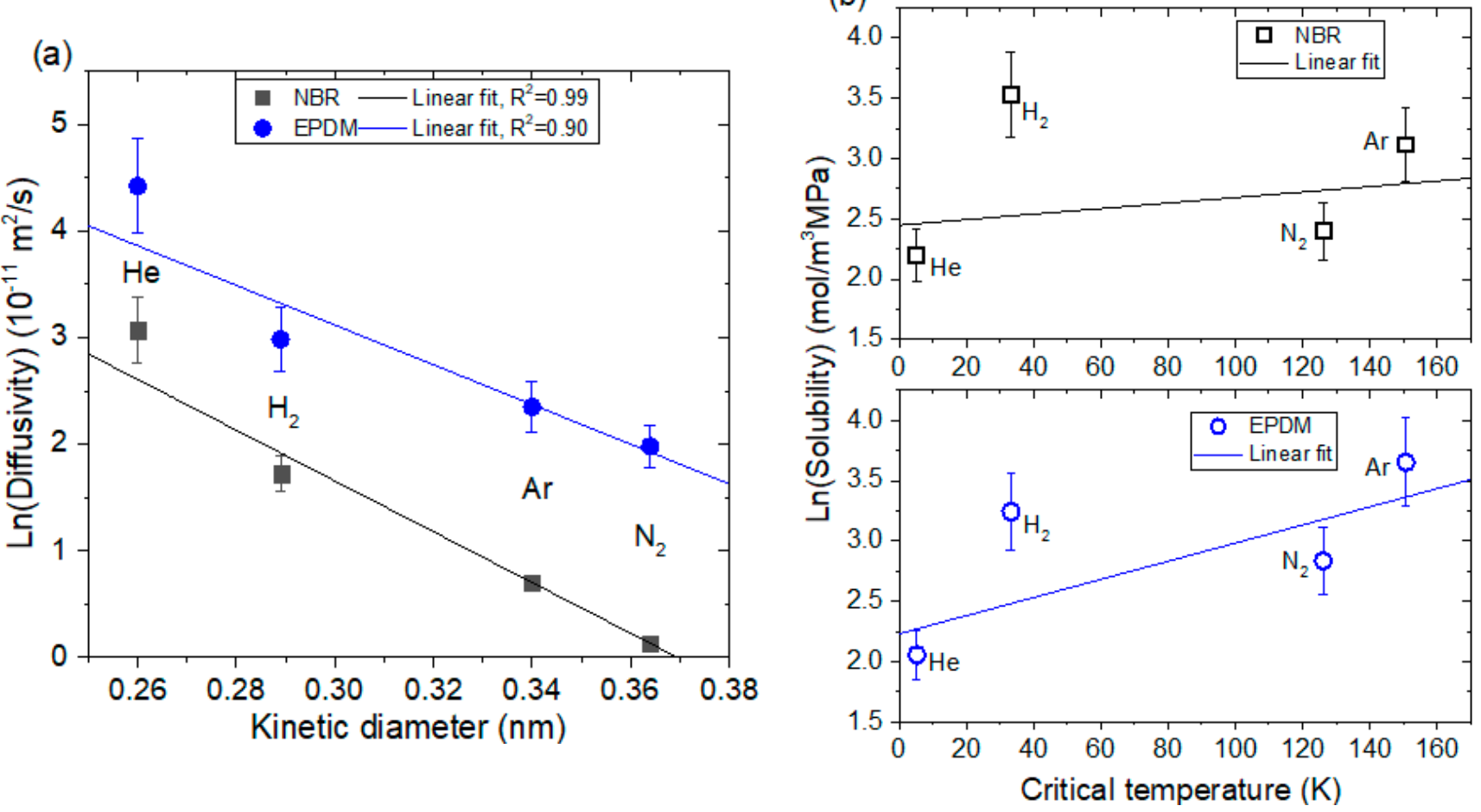

Figure 10. (a) A linear correlation between the logarithmic diffusivity and kinetic diameter and (b) a linear correlation between the logarithmic solubility and kinetic diameter of molecules in gas.

Meanwhile, the solubility of gases depends on the relative affinity between the gas and polymer, but more strongly on the penetrant condensability correlated with the gas critical temperature $\left(T_{\mathrm{c}}\right)$. The relationship between gas solubility and the critical temperature is generally expressed as [26,27]:

$$
\ln S=\mathrm{a}+\mathrm{b} T_{\mathrm{c}}
$$

The constant " $a$ " is a measure of the overall sorption capacity, while slope " $b$ " indicates the increase in solubility with regard to the penetrant condensability. Figure 10b demonstrates the solubility of the four gases versus critical temperature for two polymers. It is observed for EPDM rather than NBR that the logarithmic solubility increases nearly linearly with the increase in the critical temperature, except for $\mathrm{H}_{2}$ gas, which deviates from linearity. A similar relationship was reported for polyvinylpyridine film [27].

We present the performance parameters of capacitor sensors, such as sensitivity, resolution, stability, detection range, and response time, for the two sensors in Table 2 with a related description.

Table 2. Comparison of the performance parameters of capacitor sensors.

\begin{tabular}{ccc}
\hline Parameter & Coaxial-Cylindrical & Semi-Cylindrical \\
\hline Sensitivity & $\sim 3 \mathrm{pF} / \mathrm{mL}$ & $\sim 1 \mathrm{pF} / \mathrm{mL}$ \\
Resolution & $\sim 0.5 \mathrm{wt} \cdot \mathrm{ppm}$ & $\sim 2 \mathrm{wt} \cdot \mathrm{ppm}$ \\
Stability & $<10 \mathrm{wt} \cdot \mathrm{ppm}$ & $<15 \mathrm{wt} \cdot \mathrm{ppm}$ \\
Detection range & $\sim$ max $1000 \mathrm{wt} \cdot \mathrm{ppm}$ for $\mathrm{H}_{2}$ & $\sim$ max $1000 \mathrm{wt} \cdot \mathrm{ppm}$ for $\mathrm{H}_{2}$ \\
Response time & $<1 \mathrm{~s}$ & $<1 \mathrm{~s}$ \\
\hline
\end{tabular}

The sensitivity is defined as the slope obtained by the change in capacitance with regard to the water level in the unit of ml. The sensitivity is the most important factor deciding the performance of a sensor. The coaxial-cylindrical capacitor sensor with a high sensitivity and minute resolution could be a better choice. 


\section{Conclusions}

We first developed an automatic technique for determining the permeation of various gases, including $\mathrm{H}_{2}, \mathrm{He}, \mathrm{N}_{2}$, and Ar. This simple and effective method combines a volumetric measurement using a graduated cylinder with water level detection by capacitance measurement with two different types of electrodes in real time. This technique is able to simultaneously evaluate three sets of diffusion characteristics of gas by quantitatively analyzing the amount of gas released after high-pressure gas charging and subsequent decompression. With the autoreading and autocontrol of temperature and pressure sensors, fluctuations due to variations in the temperature and pressure of the laboratory environment were removed, resulting in good-quality permeation data. The results achieved for polymers demonstrate that the $\mathrm{H}_{2}$ permeation properties determined by the developed method are in agreement with those determined by the differential pressure method and gas chromatography.

The experimental investigation indicates that the gas content emitted from the NBR and EPDM satisfied Henry's law up to a pressure of $9 \mathrm{MPa}$, which confirmed that the content was primarily proportional to the pressure. The solubility and diffusivity were identical for all specimens employed, regardless of the sample shape and dimensions. This is a general trend, but different diffusivity values were found for thicker specimens. The different diffusivities for each gas can be attributed to the different kinetic diameters of the molecules in the gas.

In conclusion, a technique for determining permeation with capacitance measurement using a frequency response analyzer could be effectively applied for automatically evaluating the transport properties of gases in polymers and other materials for cases requiring real-time and time-consuming measurements with a slow diffusion rate. This simple technique could be applied in permeation evaluation and leakage tests for all types of gas without sample size and shape limitations.

Author Contributions: Conceptualization, J.J.; methodology, J.J. and G.K.; software, G.K. and G.G.; validation, C.P. and J.L.; formal analysis, G.G. and J.L.; writing—original draft preparation, J.J.; writing-review and editing, J.J. All authors have read and agreed to the published version of the manuscript.

Funding: This research was supported by Development of Reliability Measurement Technology for Hydrogen Fueling Station funded by the Korea Research Institute of Standards and Science (KRISS-2022-GP2022-0007).

Institutional Review Board Statement: Not applicable.

Informed Consent Statement: Not applicable.

Data Availability Statement: The data used to support the findings of this study are available from the corresponding author upon request.

Acknowledgments: This research was supported by Development of Reliability Measurement Technology for Hydrogen Fueling Station funded by the Korea Research Institute of Standards and Science (KRISS-2022-GP2022-0007). This research was supported by Basic Science Research Program through the National Research Foundation of Korea(NRF) funded by the Ministry of Education(NRF2020R1I1A1A01064234)(Changyoung Park).

Conflicts of Interest: The authors declare that they have no known competing financial interest or personal relationship that could have appeared to influence the work reported in this paper. 


\section{References}

1. Mitchell, M.; Link, R.; Severin, J.; Bix, L.; Linz, J.; Gilliland, D.; Lockhart, H. A new methodology for whole-package microbial challenge testing for medical device trays. J. Test. Eval. 2007, 35, 373-380. [CrossRef]

2. Siracusa, V. Food packaging permeability behaviour: A report. Int. J. Polym. Sci. 2012, 2012, 1-11. [CrossRef]

3. Tseng, H.H.; Lin, Z.Y.; Chen, S.H.; Lai, W.H.; Wey, M.Y. Reuse of reclaimed tire rubber for gas-separation membranes prepared by hot-pressing. J. Clean. Prod. 2019, 237, 117739. [CrossRef]

4. Oriyama, T.; Yamamoto, T.; Yanagihara, Y.; Nara, K.; Abe, T.; Nakajima, K.; Aoyama, T.; Suzuki, H. Evaluation of the permeation of antineoplastic agents through medical gloves of varying materials and thickness and with varying surface treatments. J. Pharm. Health Care Sci. 2017, 3, 13. [CrossRef]

5. George, S.; Ninan, K.; Thomas, S. Permeation of nitrogen and oxygen gases through styrene-butadiene rubber, natural rubber and styrene-butadiene rubber/natural rubber blend membranes. Eur. Polym. J. 2001, 37, 183-191. [CrossRef]

6. BS EN ISO 2556; Plastics-Determination of the Gas Transmission Rate of Films and Thin Sheets under Atmospheric PressureManometric Method. 2001. Available online: https:/ /www.en-standard.eu/une-en-iso-2556-2001-plastics-determination-of-thegas-transmission-rate-of-films-and-thin-sheets-under-atmospheric-pressure-manometric-method-iso-2556-1974 (accessed on 27 January 2022).

7. Monson, L.; Moon, S.I.; Extrand, C. Gas permeation resistance of various grades of perfluoroalkoxy-polytetrafluoroethylene copolymers. J. Appl. Polym. Sci. 2009, 111, 141-147. [CrossRef]

8. Minelli, M.; Sarti, G.C. Gas transport in glassy polymers: Prediction of diffusional time lag. Membranes 2018, 8, 8. [CrossRef]

9. Mukaddam, M.; Litwiller, E.; Pinnau, I. Gas sorption, diffusion, and permeation in nafion. Macromolecules 2016, 49, $280-286$. [CrossRef]

10. Mamaliga, I.; Schabel, W.; Kind, M. Measurements of sorption isotherms and diffusion coefficients by means of a magnetic suspension balance. Chem. Eng. Process. Process Intensif. 2004, 43, 753-763. [CrossRef]

11. Markočič, E.; Škerget, M.; Knez, Ž. Measurement of $\mathrm{CO}_{2}$ solubility and diffusivity in poly(l-lactide) and poly(d, l-lactide-coglycolide) by magnetic suspension balance. J. Supercrit. Fluids 2008, 47, 296-301. [CrossRef]

12. Liu, L.B.; Hashi, Y.; Qin, Y.P.; Zhou, H.X.; Lin, J.M. Development of automated online gel permeation chromatography-gas chromatograph mass spectrometry for measuring multiresidual pesticides in agricultural products. J. Chromatogr. B Anal. Technol. Biomed. Life Sci. 2007, 845, 61-68. [CrossRef]

13. Bemporad, D.; Essex, J.W.; Luttmann, C. Permeation of small molecules through a lipid bilayer: A computer simulation study. J. Phys. Chem. B 2004, 108, 4875-4884. [CrossRef]

14. Barth, T.; Herbin, R.; Ohlberger, M. Finite volume methods: Foundation and analysis. In Encyclopedia of Computational Mechanics, Stein, E., Borst, R.D., Hughes, T.J.R., Eds.; John Wiley and Sons: New York, NY, USA, 2017.

15. Jung, J.K.; Kim, I.G.; Kim, K.T.; Ryu, K.S.; Chung, K.S. Evaluation techniques of hydrogen permeation in sealing rubber materials. Polym. Test. 2021, 93, 107016. [CrossRef]

16. Jung, J.K.; Kim, I.G.; Kim, K.T. Evaluation of hydrogen permeation characteristics in rubbery polymers. Curr. Appl. Phys. 2021, 21, 43-49. [CrossRef]

17. Basel, I.I.; Wael, H.A. Innovative techniques for two-phase flow measurements. Recent Patents Electr. Eng. 2008, 1, 1-13. [CrossRef]

18. Dangjuan, L.; Tang, L.; Shenjiang, W.; Huan, X.; Bin, W. The liquid level measurement of ultra low temperature cylinder based on the relative capacity method. In Proceedings of the 4th National Conference on Electrical, Electronics and Computer Engineering (NCEECE 2015), Xi'an, China, 12-13 December 2015; pp. 1061-1066.

19. Crank, J. The Mathematics of Diffusion; Oxford University Press: Oxford, UK, 1975.

20. Yang, Y.; Liu, S. Estimation and modeling of pressure-dependent gas diffusion coefficient for coal: A fractal theory-based approach. Fuel 2019, 253, 588-606. [CrossRef]

21. Nelder, J.A.; Mead, R. A simplex method for function minimization. Comput. J. 1965, 7, 308-313. [CrossRef]

22. Sander, R. Compilation of Henry's law constants (Version 4.0) for water as solvent. Atmos. Chem. Phys. 2015, 15, 4399-4981. [CrossRef]

23. Jung, J.K.; Kim, K.T.; Chung, K.S. Two volumetric techniques for determining the transport properties of hydrogen gas in polymer. Mater. Chem. Phys. 2022, 276, 125364. [CrossRef]

24. Mehio, N.; Dai, S.; Jiang, D.E. Quantum mechanical basis for kinetic diameters of small gaseous molecules. J. Phys. Chem. A 2014, 118, 1150-1154. [CrossRef]

25. Liu, Q.; Cai, Z. Study on the characteristics of gas molecular mean free pathin nanopores by molecular dynamics simulations Int. J. Mol. Sci. 2014, 15, 12714-12730. [CrossRef] [PubMed]

26. Li, X.G.; Kresse, I.; Xu, Z.K.; Springer, J. Effect of temperature and pressure on gas transport in ethyl cellulose membrane. Polymer 2001, 42, 6801-6810. [CrossRef]

27. Shieh, J.J.; Chung, T.S. Gas permeability, diffusivity, and solubility of poly(4-vinylpyridine) film. J. Polym. Sci. Part B 1999, 37, 2851-2861. [CrossRef] 